\title{
Slight femoral under-correction versus neutral alignment in total knee arthroplasty with preoperative varus knees: a comparative study
}

\author{
Kai Lei ${ }^{\dagger}$, Li-Ming Liu ${ }^{\dagger}$ (C) , Peng-Fei Yang, Ran Xiong, De-Jie Fu, Liu Yang and Lin Guo* (i)
}

\begin{abstract}
Background: This study aimed to compare the short-term clinical results of slight femoral under-correction with neutral alignment in patients with preoperative varus knees who underwent total knee arthroplasty.

Methods: The medical records and imaging data were retrospectively collected from patients who had undergone total knee arthroplasty in our hospital from January 2016 to June 2019. All patients had varus knees preoperatively. Upon 1:1 propensity score matching, 256 patients (256 knees) were chosen and divided into a neutral alignment group ( $n=128)$ and an under-correction group $(n=128)$. The patients in the neutral group were treated with the neutral alignment. In the under-correction group, the femoral mechanical axis had a $2^{\circ}$ under-correction. The operative time, tourniquet time and the length of hospital stay in the two groups were recorded. The postoperative hip-kneeankle angle, frontal femoral component angle and frontal tibial component angle were measured. Patient-reported outcome measures were also compared.
\end{abstract}

Results: The operative time, tourniquet time and the length of hospital stay in the under-correction group were significantly shorter than the neutral alignment group $(P<0.05)$. At the 2 -year follow-up, the under-correction group had a larger varus alignment $(P<0.05)$ and a larger frontal femoral component angle $(P<0.05)$, and the frontal tibial component angles of the two groups were comparable. Compared with the neutral alignment group, the slight femoral under-correction group had significantly better patient-reported outcome measures scores $(P<0.05)$.

Conclusion: For varus knees treated with total knee arthroplasty, alignment with a slight femoral under-correction has advantages over the neutral alignment in terms of the shorter operative time and better short-term clinical results.

\section{Level of evidence: III}

Keywords: Total knee arthroplasty, Knee replacement, Varus knee, Under-correction, Mechanical alignment, Adjusted mechanical alignment, Propensity score matching

*Correspondence: guolin6212@163.com

†Kai Lei and Li-Ming Liu contributed to the work equally and should be regarded as co-first authors.

Center for Joint Surgery, Southwest Hospital, Third Military Medical University (Army Medical University), No. 30 Gaotanyan Street, Shapingba District, 400038 Chongqing, China

\section{Introduction}

Total knee arthroplasty (TKA) represents one of the most effective treatments for end-stage knee osteoarthritis. However, patient satisfaction following TKA is less than $80 \%$ due to several factors $[1,2]$. Among them, the alignment philosophy has aroused particular attention [3-9]. original author(s) and the source, provide a link to the Creative Commons licence, and indicate if changes were made. The images or other third party material in this article are included in the article's Creative Commons licence, unless indicated otherwise in a credit line to the material. If material is not included in the article's Creative Commons licence and your intended use is not permitted by statutory regulation or exceeds the permitted use, you will need to obtain permission directly from the copyright holder. To view a copy of this licence, visit http://creativecommons.org/licenses/by/4.0/. 
In TKA, restoring neutral mechanical axis alignment has been a longstanding principle, aiming to achieve balanced load distribution and improve the components' durability and clinical outcomes. However, Bellemans et al [10] found that most of the normal knee joints had a constitutional varus deformity, with an average varus hip-knee-ankle (HKA) angle of $1.3^{\circ} \pm 2.3^{\circ}$ (mean \pm standard deviation) in healthy adults. About $62 \%$ of normal adults had varus knees and $25 \%$ of them had larger varus angles $\left(>3^{\circ}\right)$ [10]. Miller et al [11] found the static alignment could not be used to predict the dynamic loading of knee joints. The studies on gait showed that the loading of medial and lateral compartments was similar in the involuntary heel touch stage [12, 13]. Therefore, an alignment philosophy named "under-correction" was introduced [14-23], emphasizing an appropriate residual mal-alignment in TKA. Multiple studies showed that the postoperative varus alignment might not influence the clinical outcomes $[17,19,24,25]$. Slight under-correction ( $3^{\circ}$ to $6^{\circ}$ of varus angle) may benefit the clinical outcomes in patients with preoperative varus knees $[16,18]$.

Currently, under-correction remains a controversial topic because those early studies were based on the relationship between the clinical outcomes and alignment on the basis of the postoperative HKA angle [17, 18, 23]. Until now, few studies have examined whether slight femoral under-correction outperforms the neutral alignment in terms of clinical outcomes.

The purpose of this retrospective study was to compare the slight femoral under-correction with the neutral alignment in patients who underwent TKA with preoperative varus knees. We also compared the outcomes of the two techniques through a short-term follow-up.

\section{Materials and methods}

This study has been approved by the Medical Ethics Committee of the First Hospital Affiliated to Army Medical University, the Chinese People's Liberation Army (No. KY2020105).

The medical records and imaging data were retrospectively collected from a series of TKAs performed by the same senior surgeon in our hospital from January 2016 to June 2019. The inclusion criteria were (1) knee osteoarthritis; (2) a confirmed preoperative varus knee deformity based on HKA angle; (3) TKAs with personalized threedimensional reconstruction as per preoperative planning [26]; (4) the same primary posterior-stabilized component (Legion ${ }^{\circledR}$ Total Knee System, Smith-Nephew, Inc., Memphis, IN, USA) used. The exclusion criteria were (1) patients without pre- or postoperative full-length weightbearing radiographs of the lower limbs (i.e., not meet Paley's criteria [27]) since it affected the measurement;
(2) patients whose follow-up data were not available; (3) the side with better outcomes in bilateral TKAs.

A total of 330 patients (330 knees) were enrolled. Based on the intraoperative alignment targets, the patients were divided into a neutral alignment group $(n=159)$ and an under-correction group $(n=171)$. A senior surgeon initially followed the mechanical alignment philosophy in this case series and gradually switched to a slight femoral under-correction $\left(2^{\circ}\right)$ in the middle and late stages based on the philosophy of adjusted mechanical alignment [28]. To reduce the influence of selection bias and potential confounding factors, age, sex, side, body mass index (BMI), and preoperative HKA angle were selected to attain a $1: 1$ propensity-score matching with the caliper set to 0.02 . Finally, each group had 128 patients (128 knees).

\section{TKA in neutral alignment group}

Operations were performed under lumbar plexus combined with sciatic nerve block anesthesia and with tourniquet control. We selected Insall's medial parapatellar approach for TKA. After the tibia was dislocated, we performed a proximal tibial osteotomy perpendicular to the tibia mechanical axis and performed a distal femoral osteotomy perpendicular to the femoral mechanical axis. To ensure the osteotomy accuracy, the procedures were performed on the basis of the personalized preoperative three-dimensional plan [26]. Then we removed the cruciate ligaments, osteophytes, and residual meniscus tissues. To balance the extension gap, we performed a three-step medial release described by Kim et al [29] as needed. A femoral rotational osteotomy was conducted with the knee flexed, referring to Whiteside's line and tibial plateau osteotomy surface. Appropriate femoral size and anteroposterior position were selected to balance flexion gap and extension gap. Once stable balance had been achieved, the prosthesis components were implanted and fixed with bone cement. The tourniquet was released when the joint cavity was rinsed. We did not perform patella replacement.

\section{TKA in under-correction group}

We performed the same surgical procedures except the distal femoral osteotomy. The bone-cutting plane was virtually perpendicular to the femoral mechanical axis with $2^{\circ}$ under-correction (Fig. 1 ).

\section{Postoperative management}

The rehabilitation program was started one day after surgery. Patients were discharged when they met all the following criteria: no obvious swelling, no extension lag, active bending $\geq 90^{\circ}$, walking distance with assistance $\geq 200 \mathrm{~m}$, and the visual analogue scale scores $\leq 4$ points. 


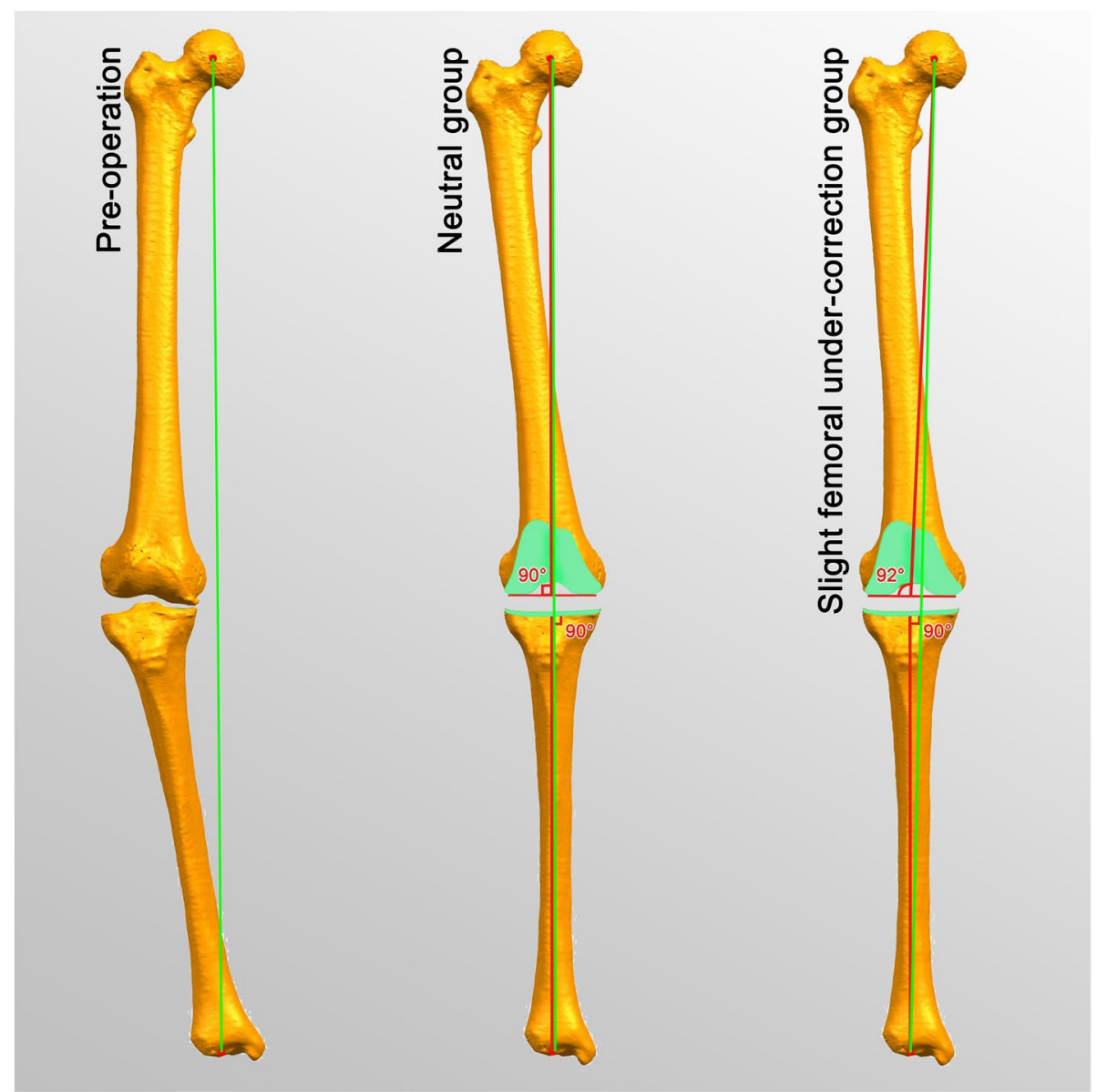

Fig. 1 Comparison of alignment targets between two groups

\section{Outcome evaluation}

A full-length weight-bearing radiograph was taken within 1 month before surgery, and the HKA angle was measured [26]. The operative time, tourniquet time, the length of hospital stay and medial soft-tissue release (performed or not) were recorded.

At the 2-year follow-up, a full-length weight-bearing radiograph was taken. The frontal femoral component angle (FFC), frontal tibial component angle (FTC), tibial component slope angle (TCS) was measured three times respectively by two blinded raters, with an interval of more than 15 days. The measurements of HKA angle, FFC, FTC and TCS are shown in Fig. 2. For the HKA angle, the varus angle was negative, and the valgus angle was positive. For tibial component slope angle, retroversion was positive and anteversion was negative. Range of motion of the joints were measured. We collected the data on patient-reported outcome measures (PROMs), including Knee Injury and Osteoarthritis Outcome Score (KOOS), New Knee Society Score (NKSS), and Western Ontario and McMaster Universities Osteoarthritis Index
(WOMAC). The WOMAC scores were standardized, ranging from 0 (worst) to 100 (best) based on the guidance proposed by Singh et al [30]. These PROMs were obtained preoperatively, 1, 6 month(s) after operation, and once every year thereafter during outpatient followups. Meanwhile, the radiolucent line, aseptic loosening and revision surgery were also recorded and analyzed.

\section{Statistical analysis}

Student $t$-test and chi-square test were performed for continuous and categorical variables, respectively. Intraclass correlation coefficient (ICC) was used to evaluate intra-rater and inter-rater consistency in full-length radiograph measurement. ICC values less than 0.5 , between 0.5 and 0.75 , between 0.75 and 0.9 , and greater than 0.90 were indicative of poor, moderate, good, and excellent reproducibility, respectively [31]. Statistical analysis was performed using SPSS 25.0 (SPSS Inc., Chicago, IL), and a $P<0.05$ was considered statistically significant. In addition, to assess whether statistical significance was 


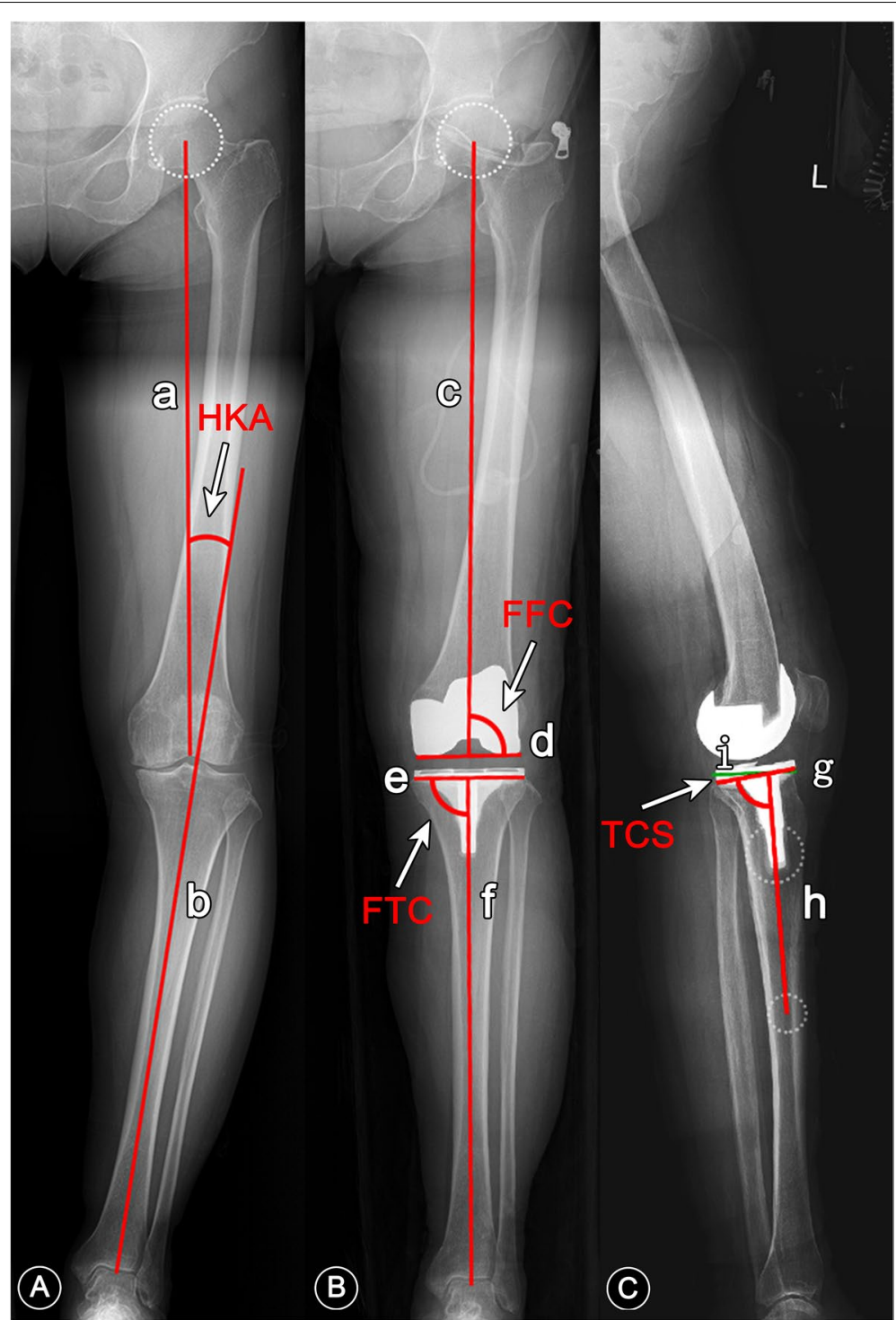

Fig. 2 Measurements of HKA angle, FFC, FTC and TCS. HKA: hip-knee-ankle; FFC: frontal femoral component angle; FTC: frontal tibial component angle; TCS: tibial component slope angle; $\mathbf{A}$ Preoperative HKA angle: the acute angle formed between the femoral mechanical axis (line a) and the tibial mechanical axis (line b). B Line c: postoperative femoral mechanical axis; line d: the line across the bottom of the femoral condyles; line e: the line across the bottom of the tibial plateau on the anteroposterior radiograph; line $\mathrm{f}$ : the postoperative tibial mechanical axis; FFC: the lateral angle between line $\mathrm{c}$ and line d; FTC: the medial angle between line e and line f; postoperative HKA angle: the acute angle between line $\mathrm{c}$ and line $\mathrm{f}$. $\mathbf{C}$ Line g: the line across the bottom of the tibial plateau on the lateral radiograph; line h: the line connecting the center points of the tibial shaft $5 \mathrm{~cm}$ and $15 \mathrm{~cm}$ below the joint line; line i is perpendicular to line $\mathrm{h}$; TCS: the acute angle between line i and line $\mathrm{g}$

clinically significant or not, a minimum clinically important difference (MCID) was introduced [32-35].

\section{Results}

All baseline data were similar between the two groups after propensity score matching (Table 1 ).

The intra-rater and inter-rater consistency in fulllength radiograph measurement were excellent (ICC $>0.9$; $P<0.05)$. Postoperatively, the under-correction group had a significantly more varus alignment and a larger FFC angle than the neutral group $(P<0.05)$. The FTC angles of the two groups were similar $(P>0.05)$ (Table 2).

The operative time, tourniquet time, and the length of hospital stay of the under-correction group were all significantly shorter than those of the neutral group $(P<0.05)$. Fewer patients of the under-correction group underwent intraoperative medial soft tissue release $(P<0.05)$ (Table 3$)$. 
Table 1 Comparison of the between-group baseline characteristics before and after PSM

\begin{tabular}{|c|c|c|c|c|c|c|}
\hline \multirow[t]{2}{*}{ Characteristics } & \multicolumn{3}{|c|}{ Before PSM $(n=330)$} & \multicolumn{3}{|c|}{ After PSM $(n=256)$} \\
\hline & $\begin{array}{l}\text { Neutral } \\
\text { group } \\
(n=159)\end{array}$ & $\begin{array}{l}\text { Under-correction } \\
\text { group } \\
(n=171)\end{array}$ & $P$ & $\begin{array}{l}\text { Neutral } \\
\text { group } \\
(n=128)\end{array}$ & $\begin{array}{l}\text { Under-correction } \\
\text { group } \\
(n=128)\end{array}$ & $P$ \\
\hline Gender (Male: Female) & $22: 137$ & $44: 127$ & $0.007^{b}$ & $22: 106$ & 19:109 & $0.609^{b}$ \\
\hline Side (Left: Right) & $79: 80$ & $83: 88$ & $0.835^{b}$ & $64: 64$ & $60: 68$ & $0.617^{b}$ \\
\hline Age (year) & $63.63 \pm 8.45$ & $66.74 \pm 8.00$ & $0.001^{\mathrm{a}}$ & $64.44 \pm 8.72$ & $65.23 \pm 7.78$ & $0.441^{\mathrm{a}}$ \\
\hline BMI $\left(\mathrm{kg} / \mathrm{m}^{2}\right)$ & $25.23 \pm 3.17$ & $25.48 \pm 3.25$ & $0.472^{\mathrm{a}}$ & $25.12 \pm 3.27$ & $25.53 \pm 3.34$ & $0.316^{\mathrm{a}}$ \\
\hline Pre-HKA angle (degree) & $-10.89 \pm 5.54$ & $-11.72 \pm 6.05$ & $0.197^{\mathrm{a}}$ & $-12.21 \pm 5.25$ & $-11.27 \pm 6.13$ & $0.190^{\mathrm{a}}$ \\
\hline
\end{tabular}

PSM propensity score matching, BMI body mass index, HKA hip-knee-ankle, For HKA angle, varus was negative and valgus was positive

a stands for student $t$-test

b stands for chi-square test; data are recorded as number or mean \pm standard deviation

Table 2 Comparison of the between-group postoperative alignment and components position at 2-year follow-up

\begin{tabular}{llll}
\hline & $\begin{array}{l}\text { Neutral group } \\
(\boldsymbol{n}=\mathbf{1 2 8})\end{array}$ & $\begin{array}{l}\text { Under- } \\
\text { correction } \\
\text { group } \\
(\boldsymbol{n}=\mathbf{1 2 8})\end{array}$ & $\boldsymbol{P}$ \\
\hline HKA angle (mean \pm SD) & $-0.68^{\circ} \pm 3.35^{\circ}$ & $-2.56^{\circ} \pm 2.81^{\circ}$ & $<\mathbf{0 . 0 0 1 ^ { \mathrm { a } }}$ \\
FFC (mean \pm SD) & $90.37^{\circ} \pm 2.33^{\circ}$ & $91.94^{\circ} \pm 1.98^{\circ}$ & $<\mathbf{0 . 0 0 1 ^ { \mathrm { a } }}$ \\
FTC (mean \pm SD) & $89.72^{\circ} \pm 2.00^{\circ}$ & $89.44^{\circ} \pm 2.10^{\circ}$ & $0.264^{\mathrm{a}}$ \\
TCS (mean \pm SD) & $5.16^{\circ} \pm 3.80^{\circ}$ & $5.35^{\circ} \pm 2.59^{\circ}$ & $0.633^{\mathrm{a}}$ \\
HKA angle $<-3^{\circ}$ Or $>3^{\circ}(n)$ & 42 & 53 & $0.155^{\mathrm{b}}$ \\
FTC $<87^{\circ}$ or $>93^{\circ}(n)$ & 14 & 18 & $0.450^{\mathrm{b}}$ \\
\hline
\end{tabular}

HKA hip-knee-ankle, FFC frontal femoral component angle, FTC frontal tibial component angle, TCS tibial component slope angle. For HKA angle, varus was negative and valgus was positive; for TCS, retroversion was positive and anteversion was negative

a stands for student $t$-test

${ }^{\mathrm{b}}$ stands for chi-square test; data are recorded as number or mean \pm standard deviation

Table 3 Comparison of the between-group surgical data

\begin{tabular}{llll}
\hline & $\begin{array}{l}\text { Neutral group } \\
(\boldsymbol{n}=\mathbf{1 2 8})\end{array}$ & $\begin{array}{l}\text { Under- } \\
\text { correction } \\
\text { group } \\
(\boldsymbol{n}=\mathbf{1 2 8})\end{array}$ & $\boldsymbol{P}$ \\
\hline Operation time (min) & $83.74 \pm 19.75$ & $73.16 \pm 10.95$ & $<\mathbf{0 . 0 0 1}^{\mathbf{a}}$ \\
Tourniquet time (min) & $51.67 \pm 13.46$ & $42.56 \pm 7.28$ & $<\mathbf{0 . 0 0 1}^{\mathbf{a}}$ \\
Length of hospital stay (day) & $8.80 \pm 1.57$ & $8.27 \pm 1.41$ & $\mathbf{0 . 0 0 4}^{\mathbf{a}}$ \\
Soft tissue release $(n)$ & 59 & 32 & $<\mathbf{0 . 0 0 1}^{\mathbf{b}}$
\end{tabular}

a stands for Student $t$-test

b stands for chi-square test; data are recorded as number or mean \pm standard deviation

The preoperative KOOS, NKSS, and WOMAC were similar between the two groups. The under-correction group had significantly better KOOS, NKSS, and WOMAC scores than the neutral group at 2-year follow-up $(P<0.05)$ (Table 4$)$. No radiolucent line, aseptic loosening or revision occurred during the whole followup (mean: 3.2 years, range: $2-5$ years).

\section{Discussion}

The most important finding of this study was that a slight femoral under-correction $\left(2^{\circ}\right)$ might be associated with shorter operative time and better short-term clinical outcomes than neutral alignment in patients with preoperative varus knees.

Restoring the neutral alignment (known as mechanical alignment) is the prerequisite for a successful TKA. Although the computer-aided techniques such as navigation, patient-specific instrumentation, and robotics have achieved a more accurate neutral alignment, the postoperative patient dissatisfaction is still up to $20 \%$ [1]. Unlike the mechanical alignment procedures, the kinematic alignment technique is a "true knee resurfacing" and "pure bone procedure". The technique aims to reconstruct the anatomy of the pre-arthritic articular surface, thereby improving the clinical outcomes $[4,5$, $7,8]$. However, excessively inclined component placement may result in increased load, especially on the tibial component, resulting in quick polyethylene wear, component loosening, and even a revision [36, 37]. Therefore, the concept of adjusted mechanical alignment was introduced [28]. It is a hybrid technique between the mechanical alignment and kinematic alignment procedures, conducting slight under-correction only on the femoral side $[28,38-40]$. This technique aims at less collateral releasing and resurfacing the knee within the original soft tissue envelope. As shown in Table 2, postoperative varus alignment in the under-correction group mainly originated from the femoral side. It was consistent with our preoperative planning and the adjusted mechanical alignment philosophy. 
Table 4 Comparison of the between-group outcomes

\begin{tabular}{|c|c|c|c|c|c|}
\hline & & $\begin{array}{l}\text { Under-correction } \\
\text { group } \\
(n=128)\end{array}$ & $\begin{array}{l}\text { Neutral group } \\
(n=128)\end{array}$ & Mean difference & $P$ \\
\hline \multirow[t]{2}{*}{ Flexion range of motion (degrees) } & Pre-op & $92.34 \pm 17.62$ & $96.09 \pm 21.84$ & -3.75 & 0.132 \\
\hline & 2 years & $117.41 \pm 6.97$ & $115.89 \pm 9.19$ & 1.52 & 0.139 \\
\hline \multirow[t]{2}{*}{ KOOS pain (100 points) } & Pre-op & $37.26 \pm 14.84$ & $37.20 \pm 11.71$ & 0.07 & 0.969 \\
\hline & 2 years & $90.49 \pm 5.57$ & $80.69 \pm 10.88$ & 9.8 & $<0.001$ \\
\hline \multirow[t]{2}{*}{ Symptoms (100 points) } & Pre-op & $45.51 \pm 15.28$ & $46.01 \pm 14.72$ & -0.5 & 0.789 \\
\hline & 2 years & $83.98 \pm 7.07$ & $75.47 \pm 10.79$ & 8.51 & $<0.001$ \\
\hline \multirow[t]{2}{*}{ ADL (100 points) } & Pre-op & $40.88 \pm 13.99$ & $41.96 \pm 11.51$ & -1.08 & 0.501 \\
\hline & 2 years & $83.72 \pm 7.14$ & $72.85 \pm 8.47$ & $10.87^{\mathrm{a}}$ & $<0.001$ \\
\hline \multirow[t]{2}{*}{ Sport/Rec (100 points) } & Pre-op & $12.97 \pm 15.38$ & $13.40 \pm 15.43$ & -0.43 & 0.824 \\
\hline & 2 years & $60.04 \pm 15.79$ & $53.36 \pm 19.52$ & 6.68 & 0.003 \\
\hline \multirow[t]{2}{*}{ QOL (100 points) } & Pre-op & $18.28 \pm 16.19$ & $18.48 \pm 14.16$ & -0.20 & 0.918 \\
\hline & 2 years & $89.18 \pm 13.66$ & $78.24 \pm 18.94$ & 10.94 & $<0.001$ \\
\hline \multirow[t]{2}{*}{ NKSS symptom (25 points) } & Pre-op & $9.55 \pm 4.93$ & $9.61 \pm 2.64$ & -0.06 & 0.912 \\
\hline & 2 years & $22.06 \pm 2.27$ & $19.95 \pm 3.76$ & $2.12^{\mathrm{a}}$ & $<0.001$ \\
\hline \multirow[t]{2}{*}{ Patient satisfaction (40 points) } & Pre-op & $18.53 \pm 6.29$ & $18.61 \pm 6.15$ & -0.08 & 0.920 \\
\hline & 2 years & $36.11 \pm 2.97$ & $33.53 \pm 3.62$ & $2.58^{\mathrm{a}}$ & $<0.001$ \\
\hline \multirow[t]{2}{*}{ Patient expectations (15 points) } & Pre-op & $10.83 \pm 2.62$ & $10.64 \pm 2.55$ & 0.19 & 0.562 \\
\hline & 2 years & $11.77 \pm 2.43$ & $10.03 \pm 2.42$ & 1.73 & $<0.001$ \\
\hline \multirow[t]{2}{*}{ Functional activities (100 points) } & Pre-op & $31.21 \pm 15.11$ & $32.16 \pm 11.04$ & -0.95 & 0.568 \\
\hline & 2 years & $72.54 \pm 6.45$ & $64.97 \pm 7.25$ & $7.57^{\mathrm{a}}$ & $<0.001$ \\
\hline \multirow[t]{2}{*}{ Total score (180 points) } & Pre-op & $70.13 \pm 23.44$ & $71.02 \pm 16.49$ & -0.89 & 0.725 \\
\hline & 2 years & $142.48 \pm 9.29$ & $128.48 \pm 11.90$ & $14.00^{\mathrm{a}}$ & $<0.001$ \\
\hline \multirow[t]{2}{*}{ WOMAC pain (100 points) } & Pre-op & $44.88 \pm 15.23$ & $43.83 \pm 12.76$ & 1.05 & 0.549 \\
\hline & 2 years & $93.36 \pm 4.35$ & $83.98 \pm 9.12$ & 9.38 & $<0.001$ \\
\hline \multirow[t]{2}{*}{ Stiffness (100 points) } & Pre-op & $38 . .67 \pm 23.02$ & $36.81 \pm 20.56$ & 1.76 & 0.52 \\
\hline & 2 years & $82.42 \pm 11.89$ & $75.59 \pm 18.42$ & 6.84 & $<0.001$ \\
\hline \multirow[t]{2}{*}{ Function (100 points) } & Pre-op & $40.88 \pm 13.99$ & $41.96 \pm 11.51$ & -1.08 & 0.501 \\
\hline & 2 years & $83.72 \pm 7.14$ & $72.85 \pm 8.47$ & $10.87^{\mathrm{a}}$ & $<0.001$ \\
\hline \multirow[t]{2}{*}{ Total score (100 points) } & Pre-op & $41.53 \pm 13.1$ & $41.93 \pm 10.36$ & -0.40 & 0.787 \\
\hline & 2 years & $85.62 \pm 5.35$ & $75.40 \pm 7.48$ & $10.22^{\mathrm{a}}$ & $<0.001$ \\
\hline
\end{tabular}

KOOS Knee Injury and Osteoarthritis Outcome Score, NKSS New Knee Society Score, WOMAC Western Ontario and McMaster Universities Osteoarthritis Index

a The mean difference was greater than the corresponding minimum clinically important difference; all data were analyzed with Student $t$-test; Data are recorded as mean \pm standard deviation

Slight femoral under-correction with certain amount of varus deformity preserved reduces the need for medial soft tissue release, resulting in shorter operative time in balancing the soft tissue. Minimal intraoperative soft tissue trauma and short tourniquet time are associated with short hospital stay.

Although slight femoral under-correction procedure has achieved higher KOOS, NKSS, and WOMAC scores after 2 years, statistical significance could not represent perceptive clinical significance. Blevins et al [33] found that MCID of KOOS were 10.3 for pain, 12.0 for symptoms, 10.0 for ADL, 15.8 for Sport/Rec, and 13.2 for QOL. MCID for NKSS scores was 1.9 in symptom, 2.2 in satisfaction, and 4.1 in functional activities [34]. Parratte et al [35] believed that the differences smaller than 10 points in total NKSS scores were unlikely to be clinically relevant. Clement et al [32] demonstrated that the MCID of WOMAC was 11 for pain, 8 for stiffness, 9 for function, and 10 for the total score. Clinical differences were indeed found between the two groups in some submeasures (mean difference was greater than the corresponding MCID), as shown in Table 4.

There are possible reasons for the slight femoral under-correction outdoing the neutral alignment procedure in terms of short-term PROMs. The majority of the normal population have a slight constitutional varus 
knee alignment with an average angle of $1.3^{\circ}$ [10]. Many patients have a long history of constitutional varus deformity before varus knee osteoarthritis [20]. The mechanical alignment technique aims to create a "systematic approach" rather than restoring the patient's normal knee structure because it changes the original soft tissue envelope of the knee joint [10,23, 41]. Surgical correction of the lower limb alignment to the neutral position, specifically, in combination with medial release, may create a relatively valgus status compared to the constitutional varus deformity. The patients may feel unnatural and uncomfortable for a short period of time immediately after TKA. Besides, varus knees need more soft tissue release to attain neutral alignment, while the medial soft tissue release impairs the knee stability and affects postoperative function and rehabilitation [42-44]. Preserving certain level of varus deformity in preoperative varus knees may accomplish a more natural and comfortable status, thereby, improving patient satisfaction [7, 24, 45-48].

Parratte et al $[49,50]$ and Bonne et al $[49,50]$ found that varus alignment less than $3^{\circ}$ did not improve the survival of the component after 15 years. Magnussen et al [3, 24] and Berend et al [3, 24] believed that the varus position of tibial components should be avoided, especially a varus angle exceeding $3^{\circ}$. Therefore, slight femoral under-correction may not significantly decrease the longer-term survival of the components based on Table 2.

This study has some limitations. First, the retrospective design and single-center study might produce selection biases even though propensity score matching was performed. Second, the surgeons' skill and experience might influence the results because they improve with time. Third, our short follow-up period may not reflect the actual survival rate, and future studies based on mid- to long-term follow-ups should be performed to ascertain the component survival better.

\section{Conclusion}

For varus knees treated with TKA, alignment with a slight femoral under-correction has advantages over the neutral alignment in terms of the shorter operative time and better short-term clinical results.

\footnotetext{
Abbreviations

TKA: Total knee arthroplasty; HKA: Hip-knee-ankle; BMI: Body mass index; FFC: Frontal femoral component angle; FTC: Frontal tibial component angle; TCS: Tibial component slope angle; PROMs: Patient-reported outcome measures; KOOS: Knee Injury and Osteoarthritis Outcome Score; NKSS: New Knee Society Score; WOMAC: Western Ontario and McMaster Universities Osteoarthritis Index; ICC: Intraclass correlation coefficient; MCID: Minimum clinically important difference.
}

Acknowledgements

We thank Xin Chen and Qing Feng for their help during this research.

\section{Authors' contributions}

K. L. wrote the manuscript, LM. L. completed the data collection, PF. Y. and R. $X$. completed the data measurement, DJ. F. conducted the statistical analysis, L. G. and L. Y. conceived the idea of the study. All authors contributed to the writing of the manuscript and approved the final manuscript.

\section{Funding}

The authors received no financial support for the research, authorship, and/or publication of this article.

\section{Availability of data and materials}

All data and materials are available on reasonable request

\section{Declarations}

Ethical approval and consent to participate

Ethical approval was obtained from the local ethical committee (No. KY2020105). All procedures performed were in accordance with the ethical standards of the institutional and/or national research committee and with the 1964 Declaration of Helsinki and its later amendments or comparable ethical standards.

\section{Consent for publication}

All authors read and approved the final manuscript. The authors agreed to publish the current work in "Arthroplasty" and declare that this work is not being concurrently submitted to any other publisher.

\section{Competing interests}

L. G. is a member of the Editorial Board of Arthroplasty and other authors declare that they have no competing interests. All authors were not involved in the journal's review of or decisions related to this manuscript.

Received: 10 August 2021 Accepted: 3 November 2021

Published online: 07 January 2022

\section{References}

1. Gunaratne R, Pratt DN, Banda J, Fick DP, Khan RJK, Robertson BW. Patient dissatisfaction following total knee arthroplasty: a systematic review of the literature. J Arthroplast. 2017:32:3854-60.

2. Lee GC, Lotke PA. Can surgeons predict what makes a good TKA? Intraoperative surgeon impression of TKA quality does not correlate with Knee Society scores. Clin Orthop Relat Res. 2012;470:159-65.

3. Berend ME, Ritter MA, Meding JB, Faris PM, Keating EM, Redelman R, et al. Tibial component failure mechanisms in total knee arthroplasty. Clin Orthop Relat Res. 2004. https://doi.org/10.1097/01.blo.0000148578. 22729.0e:26-34

4. Deep K, Picard F, Clarke JV. Dynamic knee alignment and collateral knee laxity and its variations in normal humans. Front Surg. 2015;2:62.

5. Howell SM, Hodapp EE, Vernace JV, Hull ML, Meade TD. Are undesirable contact kinematics minimized after kinematically aligned total knee arthroplasty? An intersurgeon analysis of consecutive patients. Knee Surg Sports Traumatol Arthrosc. 2013:21:2281-7.

6. Jeffery RS, Morris RW, Denham RA. Coronal alignment after total knee replacement. J Bone Joint Surg (Br). 1991;73:709-14.

7. Lee YS, Howell SM, Won YY, Lee OS, Lee SH, Vahedi H, et al. Kinematic alignment is a possible alternative to mechanical alignment in total knee arthroplasty. Knee Surg Sports Traumatol Arthrosc. 2017;25:3467-79.

8. Puthumanapully PK, Harris SJ, Leong A, Cobb JP, Amis AA, Jeffers J. A morphometric study of normal and varus knees. Knee Surg Sports Traumatol Arthrosc. 2014;22:2891-9.

9. Ritter MA, Faris PM, Keating EM, Meding JB. Postoperative alignment of total knee replacement. Its effect on survival. Clin Orthop Relat Res. 1994;299:153-6. 
10. Bellemans J, Colyn W, Vandenneucker H, Victor J. The Chitranjan Ranawat award: is neutral mechanical alignment normal for all patients? The concept of constitutional varus. Clin Orthop Relat Res. 2012;470:45-53.

11. Miller EJ, Pagnano MW, Kaufman KR. Tibiofemoral alignment in posterior stabilized total knee arthroplasty: Static alignment does not predict dynamic tibial plateau loading. J Orthop Res. 2014;32:1068-74.

12. Dhaher $Y Y$, Tsoumanis AD, Houle TT, Rymer WZ. Neuromuscular reflexes contribute to knee stiffness during valgus loading. J Neurophysiol. 2005:93:2698-709.

13. Buchanan TS, Kim AW, Lloyd DG. Selective muscle activation following rapid varus/valgus perturbations at the knee. Med Sci Sports Exerc. 1996;28:870-6.

14. Rajasekaran RB, Palanisami DR, Natesan R, Rajasekaran S. Minimal undercorrection gives better outcomes following total knee arthroplasty in severe varus knees-myth or reality?-analysis of one hundred sixty two knees with varus greater than fifteen degrees. Int Orthop. 2020;44:715-23.

15. Lee HJ, Lim JW, Lee DH, Kim DH, Park YB. Slight under-correction using individualized intentional varus femoral cutting leads to favorable outcomes in patients with lateral femoral bowing and varus knee. Knee Surg Sports Traumatol Arthrosc. 2020:28:1579-86.

16. Schiffner E, Wild M, Regenbrecht B, Schek A, Hakimi M, Thelen S, et al. Neutral or natural? Functional impact of the coronal alignment in total knee arthroplasty. J Knee Surg. 2019;32:820-4.

17. Rames RD, Mathison M, Meyer Z, Barrack RL, Nam D. No impact of undercorrection and joint line obliquity on clinical outcomes of total knee arthroplasty for the varus knee. Knee Surg Sports Traumatol Arthrosc. 2018;26:1506-14

18. Lee SS, Lee H, Lee DH, Moon YW. Slight under-correction following total knee arthroplasty for a valgus knee results in similar clinical outcomes. Arch Orthop Trauma Surg. 2018;138:1011-9.

19. Boyer B, Pailhé R, Ramdane N, Eichler D, Remy F, Ehlinger M, et al. Undercorrected knees do not fail more than aligned knees at 8 years in fixed severe valgus total knee replacement. Knee Surg Sports Traumatol Arthrosc. 2018;26:3386-94.

20. Vandekerckhove PTK, Matlovich N, Teeter MG, MacDonald SJ, Howard $J$, Lanting BA. The relationship between constitutional alignment and varus osteoarthritis of the knee. Knee Surg Sports Traumatol Arthrosc. 2017:25:2873-9.

21. Vandekerckhove PJ, Teeter MG, Naudie DD, Howard JL, MacDonald SJ, Lanting BA. The impact of wear and lift-off on coronal plane alignment in TKA and implications to future constrained revision: a retrieval study. J Arthroplast. 2015:30:2017-20.

22. Luyckx T, Vanhoorebeeck F, Bellemans J. Should we aim at undercorrection when doing a total knee arthroplasty? Knee Surg Sports Traumatol Arthrosc 2015;23:1706-12.

23. Vanlommel L, Vanlommel J, Claes S, Bellemans J. Slight undercorrection following total knee arthroplasty results in superior clinical outcomes in varus knees. Knee Surg Sports Traumatol Arthrosc. 2013;21:2325-30.

24. Magnussen RA, Weppe F, Demey G, Servien E, Lustig S. Residual varus alignment does not compromise results of TKAs in patients with preoperative varus. Clin Orthop Relat Res. 2011;469:3443-50.

25. Matziolis G, Adam J, Perka C. Varus malalignment has no influence on clinical outcome in midterm follow-up after total knee replacement. Arch Orthop Trauma Surg. 2010;130:1487-91.

26. Lei K, Liu LM, Xiang Y, Chen X, Fan HQ, Peng Y, et al. Clinical value of CTbased patient-specific 3D preoperative design combined with conventional instruments in primary total knee arthroplasty: a propensity score-matched analysis. J Orthop Surg Res. 2020;15:591.

27. Paley D. Radiographic assessment of lower limb deformities. In: Principles of deformity correction. Berlin: Springer; 2002. p. 31-60.

28. Rivière C, Iranpour F, Auvinet E, Howell S, Vendittoli PA, Cobb J, et al. Alignment options for total knee arthroplasty: a systematic review. Orthop Traumatol Surg Res. 2017;103:1047-56.

29. Kim MW, Koh IJ, Kim JH, Jung JJ, In Y. Efficacy and safety of a novel threestep medial release technique in varus total knee arthroplasty. J Arthroplast. 2015;30:1542-7.

30. Singh J, Sloan JA, Johanson NA. Challenges with health-related quality of life assessment in arthroplasty patients: problems and solutions. J Am Acad Orthop Surg. 2010;18:72-82.

31. Koo TK, Li MY. A guideline of selecting and reporting intraclass correlation coefficients for reliability research. J Chiropr Med. 2016;15:155-63.
32. Clement ND, Bardgett M, Weir D, Holland J, Gerrand C, Deehan DJ. What is the minimum clinically important difference for the WOMAC index after TKA? Clin Orthop Relat Res. 2018;476:2005-14.

33. Blevins JL, Chiu YF, Lyman S, Goodman SM, Mandl LA, Sculco PK, et al. Comparison of expectations and outcomes in rheumatoid arthritis versus osteoarthritis patients undergoing total knee arthroplasty. J Arthroplast. 2019:34:1946-1952.e1942.

34. Nishitani K, Yamamoto Y, Furu M, Kuriyama S, Nakamura S, Ito H, et al. The minimum clinically important difference for the Japanese version of the new Knee Society Score (2011 KSS) after total knee arthroplasty. J Orthop Sci. 2019;24:1053-7.

35. Parratte S, Ollivier M, Lunebourg A, Verdier N, Argenson JN. Do stemmed tibial components in total knee arthroplasty improve outcomes in patients with obesity? Clin Orthop Relat Res. 2017;475:137-45.

36. Hungerford DS, Kenna RV, Krackow KA. The porous-coated anatomic total knee. Orthop Clin North Am. 1982;13:103-22.

37. Nakamura S, Tian Y, Tanaka Y, Kuriyama S, Ito H, Furu M, et al. The effects of kinematically aligned total knee arthroplasty on stress at the medial tibia: a case study for varus knee. Bone Joint Res. 2017;6:43-51.

38. De Muylder J, Victor J, Cornu O, Kaminski L, Thienpont E. Total knee arthroplasty in patients with substantial deformities using primary knee components. Knee Surg Sports Traumatol Arthrosc. 2015;23:3653-9.

39. Deep K, Eachempati KK, Apsingi S. The dynamic nature of alignment and variations in normal knees. Bone Joint J. 2015;97-b:498-502.

40. Ranawat AS, Ranawat CS, Elkus M, Rasquinha VJ, Rossi R, Babhulkar S. Total knee arthroplasty for severe valgus deformity. J Bone Joint Surg Am. 2005:87(Suppl 1):271-84.

41. Bellemans J. Neutral mechanical alignment: a requirement for successful TKA: opposes. Orthopedics. 2011;34:e507-9.

42. Howell SM, Howell SJ, Kuznik KT, Cohen J, Hull ML. Does a kinematically aligned total knee arthroplasty restore function without failure regardless of alignment category? Clin Orthop Relat Res. 2013;471:1000-7.

43. Völlner F, Fischer J, Weber M, Greimel F, Benditz A, Renkawitz T, et al. Weakening of the knee ligament complex due to sequential medial release in total knee arthroplasty. Arch Orthop Trauma Surg. 2019;139:999-1006.

44. GuY, Roth JD, Howell SM, Hull ML. How frequently do four methods for mechanically aligning a total knee arthroplasty cause collateral ligament imbalance and change alignment from normal in white patients? AAOS Exhibit Selection. J Bone Joint Surg Am. 2014;96:e101.

45. Blakeney W, Clément J, Desmeules F, Hagemeister N, Rivière C, Vendittoli PA Kinematic alignment in total knee arthroplasty better reproduces normal gait than mechanical alignment. Knee Surg Sports Traumatol Arthrosc. 2019;27:1410-7.

46. Courtney PM, Lee GC. Early outcomes of kinematic alignment in primary total knee arthroplasty: a meta-analysis of the literature. J Arthroplast. 2017;32:2028-2032.e2021.

47. Keshmiri A, Maderbacher G, Baier C, Benditz A, Grifka J, Greimel F. Kinematic alignment in total knee arthroplasty leads to a better restoration of patellar kinematics compared to mechanic alignment. Knee Surg Sports Traumatol Arthrosc. 2019;27:1529-34.

48. Li Y, Wang S, Wang Y, Yang M. Does kinematic alignment improve shortterm functional outcomes after total knee arthroplasty compared with mechanical alignment? A systematic review and meta-analysis. J Knee Surg. 2018:31:78-86.

49. Parratte S, Pagnano MW, Trousdale RT, Berry DJ. Effect of postoperative mechanical axis alignment on the fifteen-year survival of modern, cemented total knee replacements. J Bone Joint Surg Am. 2010;92:2143-9.

50. Bonner TJ, Eardley WG, Patterson P, Gregg PJ. The effect of post-operative mechanical axis alignment on the survival of primary total knee replacements after a follow-up of 15 years. J Bone Joint Surg (Br). 2011;93:1217-22.

\section{Publisher's Note}

Springer Nature remains neutral with regard to jurisdictional claims in published maps and institutional affiliations. 